\title{
The Suburethral Sling Transobturator Approach for Stress Urinary Incontinence Treatment in Women in the Maternity and Neonatology Center of Tunis (WTSC)
}

\author{
Moufalilou Aboubakar1' ${ }^{*}$, Veronique Tognifode ${ }^{2}$, Justin Denakpo', Faouzia Zouari3 \\ ${ }^{1}$ Centre Hospitalier Universitaire de la Mère et de l'Enfant (CHU-MEL), Cotonou, Benin \\ ${ }^{2}$ Faculté à Caractère Spécial de Formation Médicale, Université de Porto Novo, Porto Novo, Benin \\ ${ }^{3}$ Centre de Maternité et de Néonatologie de Tunis, Service C, Gynécologie-Obstétrique, Tunis, Tunisia \\ Email: *moufaliloua@yahoo.fr
}

How to cite this paper: Aboubakar, M., Tognifode, V., Denakpo, J. and Zouari, F. (2017) The Suburethral Sling Transobturator Approach for Stress Urinary Incontinence Treatment in Women in the Maternity and Neonatology Center of Tunis (WTSC). Open Journal of Obstetrics and Gynecology, 7, 80-85.

http://dx.doi.org/10.4236/ojog.2017.71009

Received: November 11, 2016

Accepted: January 7, 2017

Published: January 10, 2017

Copyright (c) 2017 by authors and Scientific Research Publishing Inc. This work is licensed under the Creative Commons Attribution International License (CC BY 4.0).

http://creativecommons.org/licenses/by/4.0/

\begin{abstract}
The authors, through a descriptive retrospective study have evaluated the results of surgical treatment, by Tension-Free Obturator tape (TOT) technique, of urinary incontinence in the first 68 patients operated in the Department "C" of Obstetrics and Gynecology of the Maternity and Neonatology Centre of Tunis (WTSC). The average age in those patients was $55.14 \pm 8.47$ years with extremes of 40 and 82 years. The majority of the patients $(72 \%)$ were under the age of 60 years. In sixty-one patients (89\%), no urine leak has been detected and they were healed. In three patients (4\%) there was improvement with partial recovery. Three other (4\%) did not notice any improvement after the surgery. No case of dysuria or rejection of the strip has been reported. It was concluded that the declared satisfaction rate is $93 \%$.
\end{abstract}

\section{Keywords}

Urinary Incontinence Stress, Shutter, Sling, TOT

\section{Introduction}

The rate of urinary incontinence among the adult women varies from $20 \%$ to $50 \%$ in most international reviews [1].

- In France, the rate of urinary in continence is $21 \%$ and the patients are older than 18 years.

- In USA, $20 \%$ of women report leakage to their physician [2].

- World Health Organization (WHO) reports that one third of women in the world across all categories suffer from urinary incontinence. 
The surgical management of stress urinary incontinence has resided for a long time retro pubic colposuspension techniques through laparoto my or laparoscopy.

The tension free vaginal tape (TVT) technique supporting the middle urethra without tension using a knitmonofilament strip of polypropylene was suggested by Ulmstenin 1995 [1] and has become for some years now the most used surgical procedure in the management of stress urinary incontinence.

The transobturator approach was elaborated in 2001 by Delorme and suggests a new approach passing through the obturator openings. Its morbidity and efficiency especially in the long term are controversial compared to the TVT. For others like Mellier [3], TOT presents less complication and its simplicity and safety make it the best technique.

The TOT technique recently described has not yet been published enough.

A TOT study reveals, with a twelve-month hindsight, $80.5 \%$ recovery and $7.5 \% \mathrm{im}$ provement of urinary incontinence.

Two studies were published on the short term outcomes of TOT. One has reported a success rate of $94 \%$ among 16 women followed up during a year [4].

This technique does not practically exist in sub-Saharan African countries but it is increasingly implemented in North-Africa countries such as Tunisia.

The TOT technique is suggested to patients attending the Obstetrics and Gynecology department as well as Urology department in Tunisia.

The results of this technique are evaluated through this work that was performed on 68 first operated cases in the Obstetrics and Gynecology Department C of the Maternity and Neonatology Center of Tunis (WTSC).

\section{Patients and Methods}

This is a descriptive, longitudinal, retrospective, study on the 68 first patients operated in the department for SUI using the TOT technique within January 2004 and December 2009. The patients enrolled in the study were the women presenting a SUI isolated or associated with an urogenital prolapse and the cases of urinary incontinence who have experienced another method of surgical treatment failure.

The diagnosis of SUI was placed on the demonstration of urinary leakage during exercise and maneuver of positive Bonney. The use of urodynamics was not systematical.

The patients were operated on by the same surgeon, using the same technique using a sling monofilament polypropylene (MONARC) and two helical needles for implantation of the sling through transobturator.

All patients were reviewed for a post-operative control.

The results have been evaluated:

Objectively by clinical examination: were considered cured patients who did not exhibiturinary leak on effort. Partial amelioration was noticed when the patient still had urinary leakage but to alesser degree than before the intervention. It was concluded failure when no improvement was noted.

Subjectively by the level of improvement experienced and reported by patients, classified as a satisfaction score: very satisfied (complete disappearance of the symptomatology and functional constraint) satisfied (very significant improvement in the symptoms and not disabling constraint), moderately satisfied (small improvement, patient is 
still embarrassed but to a lesser degree) and not satisfied (patient reported the same functional disability).

\section{Results}

\subsection{Patients Features}

The patients features are presented in Table 1.

The average age was $55.14 \pm 8.47$ years with extremes of 40 and 82 years. The majority of our patients (72\%) were aged under 60 .

The main parity of the patients was 5 with ranging between 1 to 14 . The majority of them was multiparous and in 51 the parity was greater than 4 .

A pathological medical history of diabetes and chronic cough was noted respectively in 8 and 16 patients and 47 patients were men auposed.

In $52(76 \%)$ patients a genital prolapsed was noticed.

\subsection{Complications}

No complications related to the anesthetic technique were recorded and no case of hematoma, vaginal or bladder injury was reported.

Three cases of urinary retention (4\%) were noted, requiring the maintenance with in dwelling catheter.

Table 1. Socio demographic and clinical characteristics of patients.

\begin{tabular}{|c|c|c|}
\hline & Number & Percentage (\%) \\
\hline \multicolumn{3}{|l|}{ AGE (years) } \\
\hline$[40-50]$ & 20 & 29 \\
\hline$[50-60]$ & 29 & 43 \\
\hline$[60-70]$ & 16 & 24 \\
\hline$>70$ & 03 & 04 \\
\hline \multicolumn{3}{|l|}{ PARITY } \\
\hline Primiparous & 01 & 01 \\
\hline Pauciparous & 04 & 06 \\
\hline Multiparous & 12 & 18 \\
\hline Big multipaorus & 51 & 75 \\
\hline \multicolumn{3}{|c|}{ PAST MEDICAL HISTORY } \\
\hline Diabetes & 08 & 11 \\
\hline Chroniccough & 16 & 22 \\
\hline \multicolumn{3}{|c|}{ HORMONAL STATUS } \\
\hline Yes & 47 & 69 \\
\hline No & 21 & 31 \\
\hline \multicolumn{3}{|c|}{ GENITAL PROLAPSE } \\
\hline Yes & 52 & 76 \\
\hline No & 16 & 24 \\
\hline
\end{tabular}

Primiparous: one delivery; pauciparous: 2 or 3 deliveries; multiparous: 4 or 5 deliveries; big multiparous: more than 5 deliveries. 


\subsection{Evaluation of Results}

All patients were reviewed at two weeks and one month under a post-operative control. The follow-up of the patients ranged has varied within 2 months and 2 years depending on the surgery date.

\subsubsection{Objective Evaluation}

In sixty-one patients (89\%), no urine leak has been detected during the post operative control. They were therefore considered as healed. On three patients (4\%), there was a partial improvement. Three other $(0.4 \%)$ did not notice any improvement after the surgery, which was confirmed by clinical examination. It is a surgical failure. One case (01\%) of de novo urge was noted. No case of dysuria or rejection of the strip has been reported (Figure 1).

\subsubsection{Subjective Evaluation}

The results of the subjective evaluation are presented in Table 2.

63 in 68 patients said that they were satisfied with the TOT service provided:

- 61 patients were very satisfied and

- 02 weresatisfied.

It was concluded that the satisfaction rate is $93 \%$.

\section{Discussion}

Various studies have shown that the rate of urinary incontinence increases progressively with age. With the improvement of the life expectancy of women, the frequency of pelvic floor disorders and stress incontinence area is clearly increasing. Its prevalence is high affecting between $10 \%$ and $58 \%$ of women [5] [6]. A first peak rate of urinary incontinence was found around the age of 50 years, around the menopause and a second peak beyond 70years of age, the end of life [7].

In our study the average age was $55.14 \pm 8.47 \%$ years and $43 \%$ of patients were in the age group of 50 to 60 years confirming the first peak reported in the literature. Women over the age of 70 years accounted for only $04 \%$ of the number. This can be explained by the reduced sample size on the one hand and by the reluctance of patients to consult at that age especially as stress urinary incontinence is associated in the collective imagination harm to a natural phenomenon of aging.

Surgery of the stress urinary incontinence aims to remove urinary leakage during effort. It is indicated for urinary stress incontinence second and third degree according to the MSH scale (Measure Urinary Handicap) or a failure of rehabilitation for urinary incontinence of moderate exertion.

Two studies published on the outcome of short-term intervention by TOT found higher rates of $94 \%$ on 16 women after a follow up of 3 to 12 months [8] and 91\% (29 women on 32) after monitoring over a period of a year [9].

In our study the cure rate was $89 \%$. This rate is comparable to those found by Delorme [10] with $80 \%$ to $90 \%$ and Chene G. et al. [11] with $87 \%$. It is however higher than Melki E. et al. [12] which was 58\%.

The results of the literature review are shown in Table 3. 


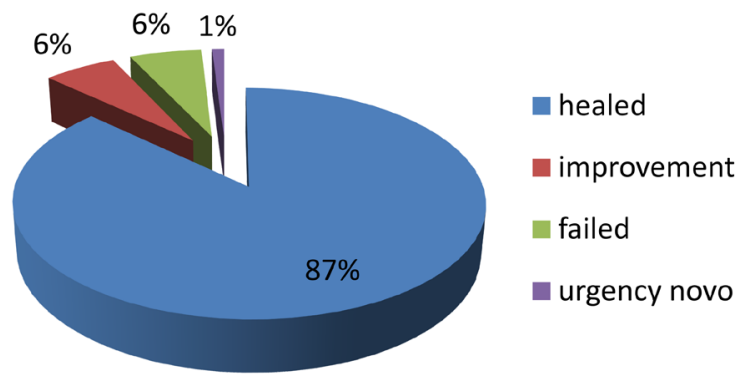

Figure 1. Distribution of patients according to the result of objective evaluation.

Table 2. Distribution of patients according to their level of satisfaction.

\begin{tabular}{ccc}
\hline Effectif & Pourcentage (\%) \\
\hline Level of satisfaction & 61 & 89.70 \\
Very satisfied & 2 & 2.94 \\
Satisfied & 1 & 1.47 \\
Fairly satisfied & 4 & 5.88 \\
No satisfied & 68 & 100.00 \\
TOTAL & 6
\end{tabular}

Table 3. The different results of the technique in the literature review.

\begin{tabular}{cccc}
\hline & Delorme [10] & Chêne G. et al. [11] & Melki E. et al. [12] \\
\hline Cure rate & $80 \%-90 \%$ & $87 \%$ & $58 \%$ \\
Improvement rate & $7 \%-9 \%$ & $13 \%$ & $31 \%$ \\
Failure & $7 \%-9 \%$ & (Improvement, failure) & $11 \%$ \\
\hline
\end{tabular}

The most reported complications include vaginal erosions and ulcers (1\% to $2 \%$ ) wounds and urethral and bladder erosions (below 1\%). These are often due to a technical error handling maneuvered of the needle in and out which may cause urethralinjury during his spacewalk of dissection between the vagina and urethra.

The obstructive complications have a frequency of the order of $2 \%$ to $3 \%$, [13]. We recorded three cases of urinary (4\%). They are generally trivial and subside fast. In our case the treatment consisted in maintaining an indwelling catheter.

\section{Conclusion}

Our study has some limitations due to the weak size of the sample, its retrospective nature and the absence of a control group. However, the treatment of SUI by the TOT technique was possible and has shown good results at the MNTC of Tunis.

\section{References}

[1] Villet, R., Salet-Lizée, D., Cortesse, A. and Zafiropulo, M. (2000) Urinary Incontinence of Women. Masson, 3-111.

[2] Villet, R., Atallah, D., Cotelle-Bernede, O., Gadonneix, P., Salee-Lizee, D. and Van Den Akker, M. (2002) Treatment of Urinary Stress Incontinence by Tensionless Sub-Urethral 
Tape (TVT). Medium-Term Results of a Prospective Study of 124 Cases. Progress in Urology, 12, 70-76.

[3] Mellier, G., Benayed, B., Bretones, S. and Pasquier, J.C. (2004) Suburethral Tape via the Obturator Route: Is the TOT a Simplification of TVT. International Urogynecology Journal and Pelvic Floor Dysfunction, 15, 227-232.

[4] Minassian, V.A., Drutz, H.P., et al. (2003) Urinary Incontinence as a Worldwide Problem. International Journal of Gynecology \& Obstetrics, 82, 327-338. https://doi.org/10.1016/S0020-7292(03)00220-0

[5] National Agency for the Development of Medical Evaluation (1995) Assessment and State of Knowledge Regarding Adult Urinary Incontinence. ANDEM, Paris.

[6] Alling Moller, L., Lose, G., et al. (2000) Risk Factors for Lower Urinary Tract Symptoms in Women 40 to 60 Years of Age. Obstetrics \& Gynecology, 96, 466-451. https://doi.org/10.1097/00006250-200009000-00022

[7] Hunskaar, S., Burgio, K., et al. (2003) Epidemiology and Natural History of Urinary Incontinence in Women. Urology, 62, 16-23. https://doi.org/10.1016/S0090-4295(03)00755-6

[8] Mining, P. (1985) Biofeedback in Rehabilitation. Psychological Medicine, 17, 1507-1508.

[9] Chaliha, C., Kalia, V., et al. (1999) Antenatal Prediction of Postpartum Urinary and Fecal Incontinence. Obstetrics \& Gynecology, 94, 689-694. https://doi.org/10.1097/00006250-199911000-00009

[10] De Tayrac, R. and Madelenat, P. (2004) Evolution of the Different Surgical Approaches in Female Urinary Incontinence. Gynécologie Obstétrique \& Fertilité, 32, 1031-1038. https://doi.org/10.1016/j.gyobfe.2004.10.019

[11] Chêne, G., Tardieu, A.S., Cotte, B., Chauleur, C., Savary, D., Krief, M., Anton-Bousquet, M.C. and Mansoor, A. (2008) Quality of Life after Stress Urinary Incontinence Cure: Comparison of Three Techniques. Gynecology Obstetrics \& Fertility.

[12] Melki, E., Monnier, B., Richard, S. and Hocké, C. (2007) Surgical Cure of Stress Urinary Incontinence by Transobturative Suburethral Tape. Gynecology Obstetrics \& Fertility, 35, 96-100. https://doi.org/10.1016/j.gyobfe.2006.11.012

[13] Hermieu, J.F. (2005) Sub-Urethral Strips in Stress Urinary Incontinence of Women: Review of the Different Processes. Annals of Urology, 9, 124-136. https://doi.org/10.1016/j.anuro.2005.08.001

\section{Submit or recommend next manuscript to SCIRP and we will provide best service for you:}

Accepting pre-submission inquiries through Email, Facebook, LinkedIn, Twitter, etc. A wide selection of journals (inclusive of 9 subjects, more than 200 journals)

Providing 24-hour high-quality service

User-friendly online submission system

Fair and swift peer-review system

Efficient typesetting and proofreading procedure

Display of the result of downloads and visits, as well as the number of cited articles

Maximum dissemination of your research work

Submit your manuscript at: http://papersubmission.scirp.org/

Or contact ojog@scirp.org 